\title{
Inovar e promover o ensino da Matemática com recurso à Astronomia ${ }^{1}$
}

\author{
Innovating and promoting the teaching of Mathematics with Astronomy \\ Maria Cristina Oliveira da Costa ${ }^{2}$ \\ António Manuel Dias Domingos ${ }^{3}$ \\ Vitor Manuel Neves Duarte Teodoro ${ }^{4}$
}

\begin{abstract}
Resumo
Este artigo descreve o impacto de um programa de formação de professores do Ensino Básico, que inclui atividades experimentais hands-on de Astronomia, nas práticas de ensino da Matemática. O programa envolve workshops com conteúdos de Matemática e Ciências, onde são trabalhadas diversas tarefas, para implementar em aula. Com uma metodologia de Teacher Design Research, investiga-se em que medida os professores inovaram as suas práticas, concebendo e implementando tarefas de Matemática, a partir de atividades experimentais hands-on de Astronomia. A recolha de dados foi feita através de observações de aulas, entrevistas e portefólios realizados pelos professores. Com uma abordagem qualitativa, de natureza interpretativa, conclui-se que os professores ganharam motivação para conceber e realizar atividades experimentais com os seus alunos, nomeadamente para promover o ensino da Matemática, a partir de atividades experimentais hands-on de Astronomia.
\end{abstract}

Palavras-chave: Desenvolvimento Profissional, Teacher Design Research, Hands-on, Interdisciplinaridade.

\begin{abstract}
This paper describes the impact of a teachers' professional development programme that involves hands-on Astronomy experiments, in mathematical teaching practices. Teachers attended workshops with mathematical and science content and produced several tasks to be implemented in the classroom. With a Teacher Design Research methodology, we investigate how teachers innovated their practices, designing and implementing mathematical tasks, from Astronomy hands-on experiments. Data collection involved participant observation, interviews and portfolios created and presented by the teachers, within the scope of the training course. With a
\end{abstract}

Submetido em: 11/12/2017 - Aceito em: 08/12/2018 - Publicado em: 12/12/2018.

${ }^{1}$ Nota dos editores: A revista Zetetiké, por respeitar as diferenças linguísticas que ainda persistem após o acordo ortográfico entre os países de língua portuguesa, optou por publicar este artigo na linguagem original dos autores.

${ }^{2}$ Doutorando em Ciências da Educação pela FCT da Universidade Nova de Lisboa, Professora Adjunta da Escola Superior de Tecnologia de Tomar, do Instituto Politécnico de Tomar, Portugal. Email: ccosta@ipt.pt

${ }^{3}$ Doutor em Ciências da Educação pela Faculdade de Ciências e Tecnologia (FCT), Universidade Nova de Lisboa, Professor Auxiliar da FCT da Universidade Nova de Lisboa, Portugal. Email: amdd@ fct.unl.pt

${ }^{4}$ Doutor em Ciências da Educação pela Faculdade de Ciências e Tecnologia (FCT), Universidade Nova de Lisboa, Professor Auxiliar da FCT da Universidade Nova de Lisboa, Portugal. Email: vdt@ @ fct.unl.pt 
DOI: http://dx.doi.org/10.20396/zet.v26i3.8651176

qualitative and an interpretative approach from the collected data, we conclude that teachers gained motivation to design and implement experiments with their students, namely enhancing the teaching of mathematics, from Astronomy hands-on experiments.

Keywords: Professional Development, Teacher Design Research, Hands-on, Interdisciplinarity.

\section{Introdução}

Este estudo descreve o impacto de um Programa de Desenvolvimento Profissional (PDP) que envolve atividades experimentais hands-on de Astronomia, no desenvolvimento de práticas de ensino da Matemática, de professores do $1 .{ }^{\circ}$ Ciclo do Ensino Básico (1. $\left.{ }^{\circ} \mathrm{CEB}\right)$. A denominação hands-on é usada num contexto no qual os próprios estudantes manipulam os materiais e observam os resultados tirando conclusões (Abrahams, Reiss \& Sharpe, 2014).

Em Portugal, alguns temas de Astronomia são abordados na área curricular de Estudo do Meio do 1. ${ }^{\circ}$ CEB no domínio "À descoberta do ambiente natural". Nos princípios orientadores da organização curricular (ME, s.d.) é referido que "o Estudo do Meio está na intersecção de todas as outras áreas do programa, podendo ser motivo e motor para a aprendizagem nessas áreas.” (p. 101). Nos objetivos gerais destaca-se que o aluno deve: "Utilizar alguns processos simples de conhecimento da realidade envolvente (observar, descrever, formular questões e problemas, avançar possíveis respostas, ensaiar, verificar), assumindo uma atitude de permanente pesquisa e experimentação" (ME, s.d., p. 103).

Segundo as indicações metodológicas, a "curiosidade infantil pelos fenómenos naturais deve ser estimulada e os alunos encorajados a levantar questões e a procurar respostas para elas através de experiências e pesquisas simples" (ME, s.d., p. 115). Nessas indicações, recomenda-se, ainda, que os alunos devem usar instrumentos de observação e medida, sendo importante que os mesmos façam registos daquilo que observam.

No que diz respeito à Matemática (ME, 2013), a análise do mundo natural é uma das três finalidades assinaladas nas orientações metodológicas:

A Matemática é indispensável a uma compreensão adequada de grande parte dos fenómenos do mundo que nos rodeia, isto é, a uma modelação dos sistemas naturais que permita prever o seu comportamento e evolução. Em particular, o domínio de certos instrumentos matemáticos revela-se essencial ao estudo de fenómenos que constituem objeto de atenção em outras disciplinas do currículo do Ensino Básico (Física, Química, Ciências Naturais, Geografia...) (ME, 2013, p. 2).

Os temas relacionados com a Astronomia são dos que mais curiosidade e interesse despertam nas crianças de ambos os géneros, ao nível do ensino básico (Lavonen, Byman, Juuti, Meisalo, \& Uitto, 2005). Tópicos como os Astros, nomeadamente o Sistema Solar, são trabalhados desde o $1 .^{\circ}$ ao $4 .^{\circ}$ ano, do $1 .^{\circ}$ CEB. Uma das aplicações à Matemática tem a ver com o tópico "Números e Operações - Números Naturais" onde é possível trabalhar números na ordem dos milhões, usando como exemplo a distância dos planetas ao Sol. Para representar o Sistema Solar já é necessário falar em escalas de conversão para "transformar" números "grandes" em números "pequenos" de forma que seja possível "representar" os tamanhos dos planetas e as respetivas órbitas e assim ficar com uma ideia das distâncias dos 
DOI: http://dx.doi.org/10.20396/zet.v26i3.8651176

planetas ao Sol, respetivos diâmetros (à escala), entre outros. No tema "Geometria e Medida localização e orientação no espaço", bem como noutros temas, são inúmeras as aplicações possíveis.

Neste artigo começamos por enquadrar a importância de promover a interdisciplinaridade entre a Matemática e as Ciências, bem como do papel dos professores neste processo. Com base em dados recolhidos em dois anos letivos (2015/2016 e 2016/2017), procura-se investigar se os professores que participaram no PDP promoveram o ensino da Matemática, a partir de atividades experimentais hands-on de Astronomia. Em particular, destacamos o estudo de caso de uma professora que ilustra uma forma de promover o ensino da Matemática com recurso a temas relacionados com a Astronomia.

\section{Revisão da Literatura}

Vários relatórios internacionais (Osborne \& Dillon, 2008; Rocard et al., 2007) identificam um declíneo no interesse dos jovens pela Matemática e Ciências, o que poderá comprometer o futuro das próximas gerações no que se refere ao desenvolvimento tecnológico e bem estar ambiental e social. Ambos os relatórios salientam a necessidade de criar novas estratégias de ensino que despertem o interesse dos estudantes por estas áreas.

Neste sentido, as Ciências devem ser usadas para promover a interdisciplinaridade, por favorecerem a aprendizagem de outras áreas curriculares (Abell \& Mcdonald, 2006) e a sua integração no currículo torna os estudantes mais bem preparados para a vida real (Beane, 1995). No entanto, apesar das várias recomendações para relacionar a Matemática com as Ciências (Berlin \& Lee, 2005), a concretização deste objetivo não é fácil (Baxter et al., 2014). Além disso, Treacy e O’Donoghue (2014) referem que há pouca investigação sobre esta integração em aula, bem como a falta de um modelo de ensino que seja adotado por todos. Estes autores defendem, ainda, que para este modelo ser eficaz tem que ser baseado em tarefas hands-on e centradas nos estudantes.

Face à reconhecida importância da literacia Matemática, Geiger et al. (2014) defendem ser fundamental desenvolver uma parceria entre investigadores e designers, que promova a integração de tarefas com abordagens pedagógicas adequadas, de forma a melhorar o ensino e aprendizagem da Matemática. Neste sentido, é crucial dar oportunidades de aprendizagem aos professores, através do desenvolvimento cuidadoso de cursos, workshops e materiais bem desenhados e administrados (Ball, 2003). Além disso, os professores devem trabalhar e experimentar, os conteúdos e tarefas que se espera que venham a desenvolver em aula, num ambiente de reflexão onde se sintam apoiados (Afonso, Neves \& Morais, 2005).

$\mathrm{Na}$ verdade, os professores são a pedra basilar de qualquer processo de renovação pedagógica (Rocard et al., 2007) e o sucesso de qualquer intervenção nas escolas não é possível sem o seu desenvolvimento profissional (Hewson, 2007), sendo necessário criar uma rede que os apoie de modo a motivá-los e contribuir para melhorar a qualidade do seu ensino (Rocard et al., 2007). 
DOI: http://dx.doi.org/10.20396/zet.v26i3.8651176

A inovação nas práticas dos professores é um aspeto chave para indicar a eficácia de um PDP (Murphy, Smith, Varley \& Raz1, 2015). Neste sentido, os mesmos autores recomendam a implementação de um PDP de professores, que lhes dê a oportunidade de desenvolver o seu conhecimento concetual e pedagógico, sendo fundamental que os mesmos adquiram confiança e competência na aplicação das abordagens propostas. Para a concretização deste objetivo é crucial apoiar os professores no decorrer do seu processo de formação (Murphy et al., 2015; Zehetmeier, Andreitz, Erlacher \& Rauch, 2015). Por fim, "as inovações devem ser apropriadas pelas pessoas que as implementam e transformadas na sua prática pessoal, de forma a terem efeitos reais" (Zehetmeier et al., 2015, p. 168).

Ball, Thames e Phelps (2008) desenvolveram uma abordagem empírica para compreender o Conhecimento de Conteúdo (CC) necessário para ensinar Matemática, onde destacam o Conhecimento de Conteúdo das Matérias a Ensinar (CCME) e o Conhecimento Pedagógico (CP). Luft, Hill, Nixon, Campbell e Dubois (2015) recomendam estender os domínios classificados por Ball et al. (2008) à área da educação em Ciências. Estes autores referem que a maioria dos estudos sobre o conhecimento para ensinar Ciências debruçam-se essencialmente sobre o $\mathrm{CP}$, sendo necessário desenvolver investigação relativamente ao CCME. Num estudo preliminar, Costa e Domingos (2017) verificaram a importância do CC de Ciências, para promover o sucesso da implementação de atividades experientais hands-on em aula, pelos professores. Neste sentido, concluem haver necessidade de continuar a investir no seu desenvolvimento profissional, de modo a aumentar a sua confiança e autonomia para inovarem as suas práticas, sendo crucial apoiá-los neste processo.

São várias as referências sobre a importância do ensino da Astronomia com rigor científico nos primeiros anos de escolaridade (Trumper, 2003), bem como relativamente às conceções de alunos e professores sobre este tema (Kalkan; Kiroglu, 2007). A Astronomia, para além de oferecer inúmeros recursos para compreender temas como o nosso planeta, estrelas e universo, tem uma grande potencialidade para integrar a Matemática (Fleisch \& Kregenow, 2013). Keeley e Sneider (2012) salientam a importância de apoiar os professores, de modo a que estes consigam ajudar os respetivos alunos a compreender melhor a Astronomia, tornando o seu ensino mais eficiente.

De acordo com o exposto, defendemos a importância de desenvolver um trabalho colaborativo, de forma a implementar um PDP que seja adequado às necessidades dos professores. Neste sentido, é fundamental muni-los de CC e CP e apoiá-los de modo a que estes consigam inovar as suas práticas, desenvolvendo e implementando atividades interdisciplinares. Face às dificuldades diagnosticadas em integrar a Matemática e as Ciências, bem como à necessidade de desenvolver investigação neste sentido, entendemos que o nosso estudo irá contribuir para a investigação dando conta de uma forma de promover esta integração, nomeadamente entre a Matemática e a Astronomia.

\section{Metodologia}

Zawojewski, Chamberlin, Hjalmarson e Lewis (2008) propõem a extensão do Design 
DOI: http://dx.doi.org/10.20396/zet.v26i3.8651176

Research ao desenvolvimento profissional dos professores, num contexto que envolve equipas de investigadores em conjunto com os professores, com vista a estudar e compreender como estes desenvolvem a sua prática. Cobb, Jackson e Dunlap (2014) referem que o objetivo de um estudo de design é investigar as possibilidades de reforços educacionais, apoiando os professores no desenvolvimento de práticas inovadoras.

Neste sentido, a metodologia de Teacher Design Research (TDR) pressupõe o desenvolvimento de um trabalho colaborativo, envolvendo equipas de investigação, sendo o principal objetivo promover o desenvolvimento profissional dos professores, levando-os a alterarem as suas práticas, com vista a melhorar todo o processo de ensino e aprendizagem (Bannan-Ritland, 2000). Esta metodologia implica a realização de vários ciclos de TDR. Neste estudo, cada ciclo consiste num ano letivo completo (setembro a junho) e os dados recolhidos dizem respeito a dois ciclos de TDR que correspondem a dois anos letivos (2015/2016 e 2016/2017).

De acordo com os autores acima referidos, foi desenvolvido um trabalho colaborativo entre professores do ensino superior, um Centro de Formação de professores e Agrupamentos de Escolas, de forma a criar e implementar um PDP adequado à região (centro de Portugal). No final de cada ciclo de TDR, é desenvolvida uma reflexão entre os investigadores (autores deste artigo), professores (que participam no programa) e a diretora do Centro de Formação, no sentido de melhorar o contexto formativo, de modo a torná-lo cada vez mais eficaz de forma a levar os professores a inovarem as suas práticas. A partir das conclusões desta reflexão resultam propostas de estratégias a implementar no ciclo seguinte de TDR.

Com uma abordagem qualitativa de natureza interpretativa, neste artigo procura-se investigar o impacto deste programa de formação contínua, nomeadamente em que medida os professores inovaram as suas práticas e como potenciaram o ensino da Matemática através de atividades experimentais relacionadas com a Astronomia.

\section{Contexto do estudo: o programa de desenvolvimento profissional de professores}

Para criar este PDP foram realizadas várias reuniões com os investigadores, a diretora do Centro de Formação e Diretores de Agrupamentos de Escolas. Algumas escolas estavam diagnosticadas por terem um fraco desenvolvimento de atividades experimentais de Ciências tal como recomendado nos programas curriculares. Face a este cenário, decidiu-se criar um programa adequado às necessidades desta região. Como as recomendações para promover a interdisciplinaridade têm vindo a aumentar, quer a nível nacional quer internacional, decidiu-se que o foco do programa seria "Matemática, Ciências e Tecnologia: Uma abordagem experimental". Os Diretores de Agrupamento podem divulgar e recomendar a participação dos professores neste programa, mas a decisão final é sempre do professor, sendo a sua inscrição no programa voluntária.

O programa de formação contínua consiste num total de 26 horas distribuídas por vários workshops com a duração de 2 a 4 horas cada, onde são introduzidos conteúdos sobre Ciências como é o caso da Astronomia. Nestas sessões, são realizadas diversas atividades 
DOI: http://dx.doi.org/10.20396/zet.v26i3.8651176

experimentais hands-on, de forma a que os professores tenham oportunidade de praticar tarefas que se espera que venham a desenvolver em aula, tal como recomendado na literatura (Afonso et al., 2005; Ball, 2003). Além disso, os professores são encorajados a desenvolverem a sua autonomia, de forma a criarem e a implementarem as suas próprias tarefas interdisciplinares.

Uma particularidade deste PDP tem a ver com o apoio prestado aos professores com visitas dos formadores às aulas dos formandos, quer para realizar atividades experimentais hands-on, com os respetivos alunos (a fim de as exemplificar) quer para os apoiar enquanto eles implementam as tarefas por eles propostas.

Após cada workshop, sobre cada um dos temas trabalhados, é solicitado aos professores que apresentem propostas de tarefas, destinadas a implementar com os seus alunos, que integrem o tema abordado com a Matemática. No final de cada ciclo de TDR, os professores apresentam uma reflexão crítica sobre o impacto da formação recebida, descrevendo as práticas desenvolvidas com os seus alunos.

\section{Participantes}

Os participantes neste estudo são professores do $1 .^{\circ} \mathrm{CEB}$, inscritos no referido PDP. Para preservar o anonimato dos mesmos, todos os nomes aqui apresentados são fictícios. No 1. ${ }^{\circ}$ ciclo de TDR participaram 14 professoras de 5 escolas do $1 .^{\circ} \mathrm{CEB}$ e no segundo ciclo 37 professores do sexo feminino e um do sexo masculino, de 14 escolas do $1 .^{\circ} \mathrm{CEB}$, com idades compreendidas entre os 35 e os 61 anos de idade todos com mais de 10 anos de experiência de ensino. Neste estudo, selecionamos alguns dos participantes no PDP, de forma a dar conta do impacto deste programa nas práticas dos mesmos. Em particular, destacamos o estudo de caso da professora Manuela que criou e implementou atividades experimentais de Astronomia e tirou partido deste tópico para trabalhar a Matemática.

\section{Recolha de dados}

A recolha de dados consistiu em questionários, teste diagnóstico, observação participante (realizada pela $1 .^{\mathrm{a}}$ autora deste artigo), entrevistas semiestruturadas e os portfolios escritos pelos professores no âmbito da sua participação neste PDP (Cohen, Lawrence \& Keith, 2007). Esta teve início na 1. a sessão de formação presencial, através de um questionário escrito, para caracterizar os professores, as suas motivações para o curso, conhecimentos sobre os temas abordados e o tipo de atividades experimentais desenvolvem com os seus alunos. $\mathrm{Na} 1$. $^{\mathrm{a}}$ sessão também foi realizado um teste diagnóstico com questões sobre conteúdos de Astronomia. Depois de 2 workshops sobre este tema, com a duração de 3 horas cada, o mesmo teste foi aplicado para aferir a evolução do $\mathrm{CC}$ dos tópicos de Astronomia abordados.

A observação participante decorreu essencialmente nos workshops da formação presencial com os professores e nas visitas às respetivas aulas. Todos os dados recolhidos foram transcritos para posterior análise de conteúdo. A triangulação dos dados foi essencialmente realizada pelo segundo e terceiro autores deste artigo. $\mathrm{O}$ terceiro autor foi o 
DOI: http://dx.doi.org/10.20396/zet.v26i3.8651176

principal responsável pelo design e pela dinamização dos workshops de Astronomia.

Ao longo das várias sessões de formação, uma das metodologias de trabalho foi o grupo focal (Morgan, 1997), para promover a reflexão sobre a formação, no sentido de melhorar as práticas desenvolvidas e, principalmente, apoiar os professores fazendo-os sentir que fazem parte deste processo colaborativo de desenvolvimento profissional.

\section{Estudo de caso da professora Manuela}

A professora Manuela, uma das participantes no programa, tinha 50 anos de idade, 28 anos de serviço e era titular de uma turma com 20 alunos do $3 .^{\circ}$ ano de escolaridade. Logo no segundo relatório, apresentado no final de janeiro de 2017, as suas propostas de atividades experimentais hands-on foram das que mais se destacaram, facto que levou a 1. a autora do artigo a pedir para acompanhar o seu trabalho, em aula, quer fazendo observações presenciais quer colaborando com o planeamento das aulas.

A professora desenvolveu um total de 5 sessões, sendo as 3 primeiras mais centradas na Astronomia e as 2 últimas dedicadas à Matemática a partir da Astronomia. Os dados recolhidos, relativos a estas sessões, decorreram da observação participante com notas de campo, fotografias das atividades e do portfolio apresentado pela professora. No final, das duas últimas sessões que decorreram em 5 e 26 de maio de 2017, respetivamente, foram realizadas entrevistas semiestruturadas a fim de aprofundar a recolha de dados.

\section{Análise e discussão dos dados}

Quando questionados sobre se costumam realizar atividades experimentais, a maioria dos professores refere que não se sente à vontade para trabalhar alguns conteúdos, por não terem os conhecimentos necessários para a sua implementação. Por exemplo, Costa et al. (2017) apresentam o caso da professora Luísa que participou no $1 .^{\circ}$ ciclo de TDR e manifestou falta de conhecimento de conteúdo especializado sobre eletricidade: Não sinto confiança para ensinar estes conteúdos porque não domino estes conceitos (...)" (Grupo focal, março 2016).

A falta de materiais necessários à sua execução também é outro dos fatores apontados, bem como as poucas horas reservadas para o Estudo do Meio ( $3 \mathrm{~h}$ por semana). No entanto, no final do $1 .^{\circ}$ ciclo de TDR, todos reconheceram a importância de realizar atividades experimentais em aula, para promover o interesse e a aprendizagem dos alunos por estas áreas. A professora Alcina que logo no 1. ${ }^{\circ}$ workshop, realizado em outubro de 2015, manifestou alguma desconfiança quanto ao ensino das ciências foi uma das mais interventivas no último grupo focal que decorreu em março de 2016:

Isto é importante! Os meus alunos nunca irão esquecer aquela aula de Astronomia dinamizada pelo formador. Nessa aula, enquanto aprendiam Astronomia também trabalharam a Matemática (...) Esta formação serviu para eu perceber a importância de realizar atividades experimentais com os meus alunos (Grupo focal, março 2016).

Este último grupo focal, relativo ao $1 .^{\circ}$ ciclo de TDR, para além de promover uma 
DOI: http://dx.doi.org/10.20396/zet.v26i3.8651176

reflexão sobre a formação recebida, também teve como objetivo preparar o 2..$^{\circ}$ ciclo de TDR, nomeadamente escolher os conteúdos que os professores consideravam mais relevantes e adequados para implementar nas suas aulas. Um dos conteúdos mais solicitados pelos professores foi a Astronomia, o que nos levou a dar protagonismo a este tema no $2{ }^{\circ}$ ciclo de TDR.

Os dois primeiros workshops do $2 .^{\circ}$ ciclo de TDR (ano letivo 2016/2017) foram destinados à Astronomia. Antes de iniciar a formação, os professores realizaram um teste diagnóstico para aferir o CC sobre os temas abordados. Após terminar os workshops sobre este tópico, o mesmo teste voltou a ser aplicado. Os resultados do mesmo, são analisados nas figuras 1 e 2.

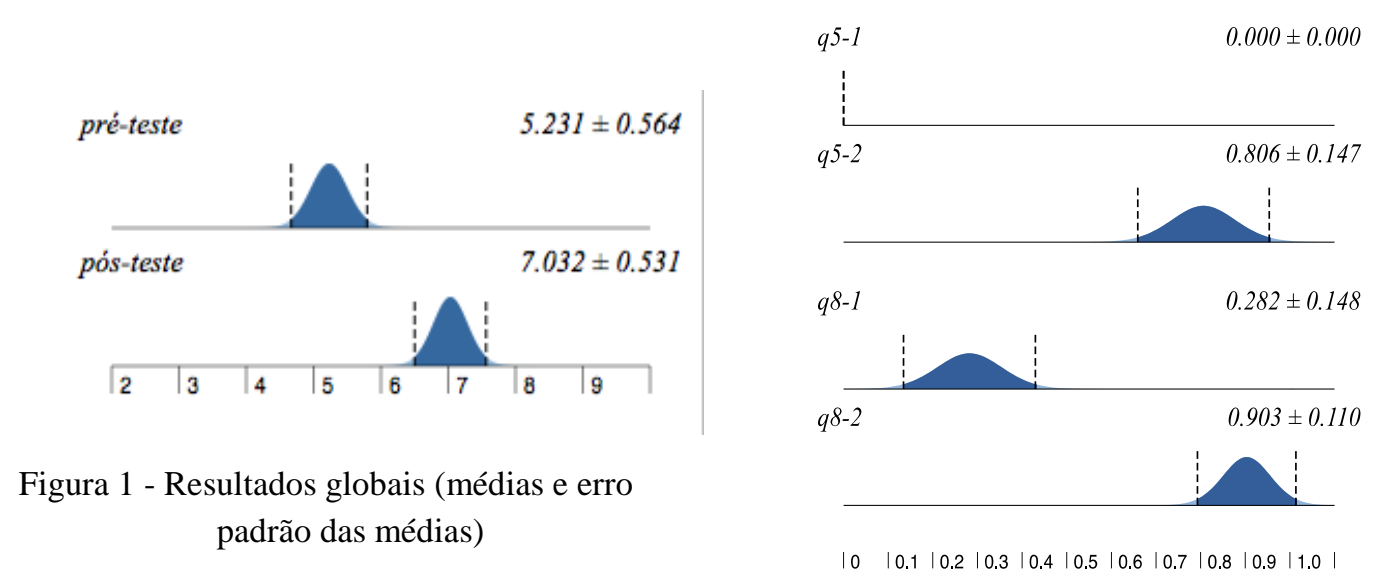

Figura 2 - Resultados dos itens 5 e 8.

A amostra trabalhada corresponde a um total de 31 professores que responderam ao teste diagnóstico nos dois momentos em que este foi aplicado. A comparação foi realizada com os dados emparelhados, tendo sido aplicado o teste $t$ de Student. Verificou-se que, após a frequência dos workshops, os participantes melhoraram significativamente os seus resultados (50\% para $70 \%$ ), relativamente ao total de respostas corretas (Figura 1). Por exemplo, nos itens 5 e 8 (Figura 2), relacionados com a órbita da Terra à volta do Sol e com a inclinação do eixo da Terra, é evidente a melhoria do CC sobre estes tópicos (de $0 \%$ para $80 \%$ e de $28 \%$ para $90 \%$, respetivamente, com um grau de confiança superior a $99 \%$ ).

No final de cada workshop foi solicitado que os professores fizessem relatórios com reflexões e propostas de atividades para implementar em aula com os respetivos alunos. As citações seguintes são exemplos de algumas dessas reflexões:

(...) Muitas das práticas realizadas na Astronomia recorrem à Matemática. Assim sendo, é relevante mostrar a aplicabilidade de vários conceitos e propriedades de conteúdos matemáticos na Astronomia. (Maria, janeiro de 2017)

(...) realizámos uma atividade prática, em que tínhamos que construir uma maquete do Planeta Terra e do Satélite Lua mais ou menos à escala. Como não tínhamos toda a informação necessária, recorremos à Wikipédia e concluímos que a Lua é cerca de quatro vezes menor que a Terra. (Idália, janeiro de 2017) 
DOI: http://dx.doi.org/10.20396/zet.v26i3.8651176

O diâmetro da Lua é $3000 \mathrm{~km}$. O raio da Terra $6400 \mathrm{~km}$. O diâmetro da Terra $12800 \mathrm{~km}$. A distância da Terra à Lua é de $400000 \mathrm{~km}$. Com estes dados construímos modelos da Terra e da Lua com massa de modelar para compreender o "raciocínio proporcional", que é a ideia mais importante do pensamento matemático e que está na base de todo o pensamento científico. (Antónia, janeiro de 2017)

Tal como muitas outras reflexões apresentadas noutros relatórios, as reflexões anteriores ilustram que os professores compreenderam a importância da Astronomia para potenciar o ensino da Matemática. Além disso, os professores adquiriram CC bem como aprenderam a usar recursos tecnológicos para o adquirirem através da internet, nomeadamente usando a Wikipédia. Por outro lado, também adquiriram CP através da atividade experimental hands-on que foi implementada para exemplificar uma forma de aplicar os conhecimentos de $\mathrm{CC}$ obtidos.

Quanto às propostas de aplicações à Matemática, apresentadas nos relatórios dos professores, apresentamos de seguida alguns exemplos:

Pesquisar na internet o diâmetro aproximado dos planetas e partindo desse valor, achar o raio de cada um. "Reduzir" o valor do raio à escala (em centímetros), desenhar utilizando o compasso os planetas. Ordenar os planetas do Sistema Solar, por ordem de tamanho (sequência crescente e decrescente) (Carlota, junho de 2017).

Ordenar figuras do sistema solar com base no seu tamanho em sequências crescentes e decrescentes. Trabalhar e representar frações recorrendo ao Planeta Terra, ao equador e Meridiano de Greenwich (Maria, fevereiro de 2017).

Qual o meu peso em cada planeta? Compreender a força de gravidade. Adquirir a noção de que o seu peso difere de planeta para planeta (Aúrea, fevereiro de 2017).

Os exemplos anteriores constituem propostas inovadoras no sentido em que estas não faziam parte das práticas habituais dos professores. No entanto, apesar de alguns professores referirem que a Matemática poderia e deveria ser integrada, estes não apresentaram propostas de como isso poderia ser feito. No final do PDP, os professores entregaram um portfolio com as reflexões finais sobre o programa e as evidências do seu trabalho desenvolvido em aula com os respetivos alunos. Os excertos seguintes destacam o apoio dos formadores neste PDP:

No decorrer desta formação, sempre pude contar com as orientações e esclarecimentos dos oradores e intervenções oportunas dos participantes. Os conteúdos foram expostos de um modo muito claro e sucinto sempre em ambiente agradável e motivador (Hélia, junho de 2017).

Os conhecimentos foram transmitidos de forma clara (...) através de exemplos concretos (...) da utilização dos materiais e realização das experiências. A estratégia, utilizada pelos formadores - promover uma dinâmica de partilha entre os formandos, (...) foi fundamental para aplicar os conhecimentos e reforçar a aprendizagem, permitindo atingir os objetivos propostos (Anabela, junho de 2017).

(...) a vinda à escola de formadores especializados, com material de experimentação, foi uma mais-valia para mim e para os meus alunos (Liliana, junho de 2017).

Considero que a ação de formação foi muito positiva. Um dos pontos mais altos, penso que é mesmo a visita dos formadores às turmas, pois, trata-se de um momento único na sala de aula (Anita, junho de 2017). 
DOI: http://dx.doi.org/10.20396/zet.v26i3.8651176

Nas reflexões anteriores fica patente a importância do apoio dos formadores no decorrer do processo de formação, nomeadamente o ambiente colaborativo de partilha de conhecimentos. Neste apoio, as visitas às escolas dos formandos é muito valorizada sendo reconhecida como "uma mais-valia" quer para os professores quer para os alunos.

Em resumo, verificamos que este PDP motivou os professores para inovarem as suas práticas através da exemplicação de atividades experimentais hands-on desenvolvidas enquanto se introduziam os conceitos teóricos. Além disso, contribuiu para munir os professores de CC sobre Astronomia e CP para implementar as práticas inovadoras em aula.

\section{A professora Manuela}

No seu relatório, após o $1 .^{\circ}$ workshop de Astronomia a professora Manuela reconhece que ganhou $\mathrm{CC}$ relacionados com a Astronomia e a Matemática, bem com CP para implementar as práticas em aula:

(...) tenho a salientar novos conhecimentos que adquiri em relação a algumas características da Terra, noções matemáticas, acontecimentos históricos e teorias pedagógicas. (...) As práticas que o formador aplicou (exercício do relógio, a modelagem da Terra e da Lua, as medições) foram uma forma de demonstrar que as interações na sala de aula contribuem para um ambiente pedagógico-didático melhorando três estratégias de sala de aula: o questionar, o responder e o utilizar materiais que facilitem a compreensão. (1. ${ }^{\circ}$ Relatório, 25/01/2017)

No segundo relatório, entregue em fevereiro de 2017, a professora apresentou atividades interdisciplinares para implementar durante 5 sessões distribuídas por 5 dias. Numa primeira entrevista, após este segundo relatório, a professora Manuela revelou que as atividades que preparou foram inspiradas na formação recebida. Como tinha introduzido na sua aula conceitos relacionados com a grandeza dos números (na ordem dos milhões) e as medições com a régua e com o compasso, procurou que estes aspetos constassem das tarefas agora propostas, relacionadas com a Matemática e com recurso à Astronomia. De seguida damos conta de como a professora conduziu algumas dessas sessões.

$\mathrm{Na} 1 .^{\mathrm{a}}$ sessão, a professora começou por solicitar aos alunos representações visuais dos seus conhecimentos, sobre a relação entre o tamanho do Sol, da Lua e da Terra; bem como o trajeto do movimento da Terra à volta do Sol, o local onde o Sol nasce e onde se põe e, ainda, identificar o Polo Norte e o Polo Sul no globo terrestre, entre outras. A figura 3 mostra desenhos feitos pelos alunos,os quais mostram algumas das suas perceções relativamente ao que lhes foi solicitado.

As duas sessões seguintes foram dedicadas à Astronomia, procurando ensinar conteúdos relacionados com este tema, de forma a corrigir as perceções, diagnosticadas na 1. ${ }^{\text {a }}$ sessão, que não correspondiam à realidade (Figura 3). 
DOI: http://dx.doi.org/10.20396/zet.v26i3.8651176

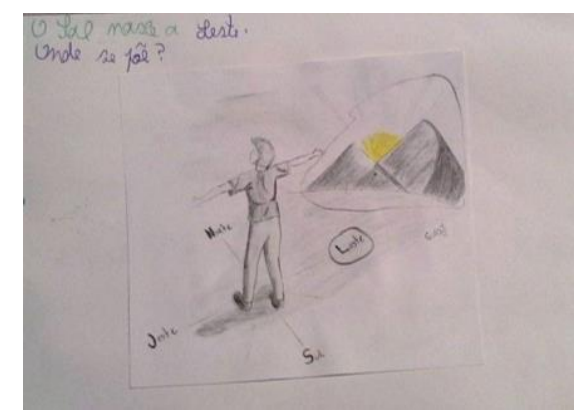

"O Sol põe-se e nasce no mesmo sítio"

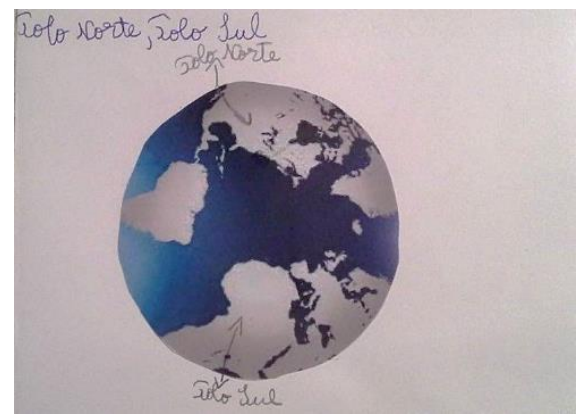

"O Polo Norte é em cima e o Polo Sul é em baixo."

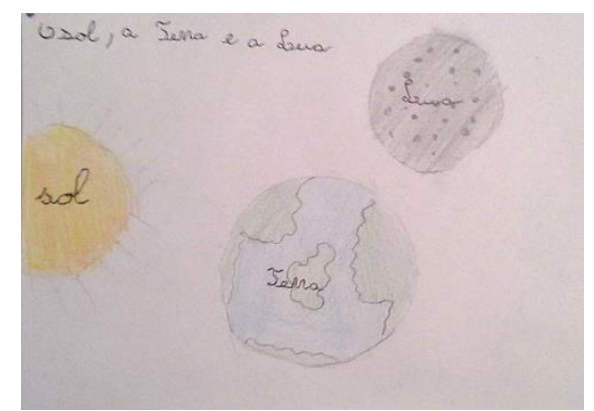

"A Terra é maior porque tem muitas pessoas."

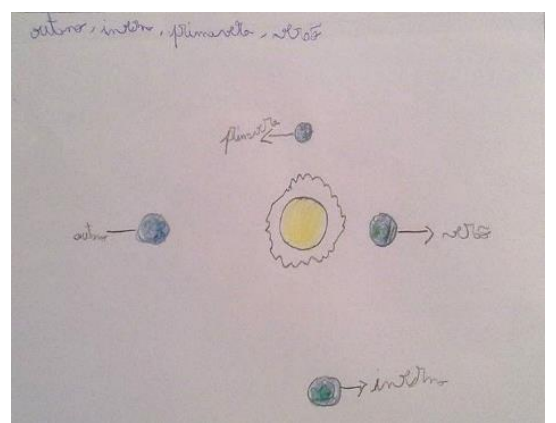

"Quando é verão a terra está mais perto do Sol"

Figura 3 - Perceções dos alunos sobre a Terra, a Lua e o Sistema Solar.

Fonte: Relatório final da Professora Manuela.

A 4. ${ }^{a}$ sessão foi dedicada a aplicar e relacionar conceitos matemáticos com os temas anteriormente abordados. A professora começou por mostrar um pequeno filme sobre o Sistema Solar (https://www.youtube.com/watch?v=7jkCIRdvGIg), com a duração de cerca de 5 minutos. De seguida, conduziu as atividades, com os alunos organizados em grupos de quatro. O Sol, com $50 \mathrm{~cm}$ de diâmetro, foi desenhado numa cartolina amarela. Um retângulo em papel com $15 \mathrm{~cm} \times 110 \mathrm{~cm}$ foi recortado para colocar os planetas (Figura 4).
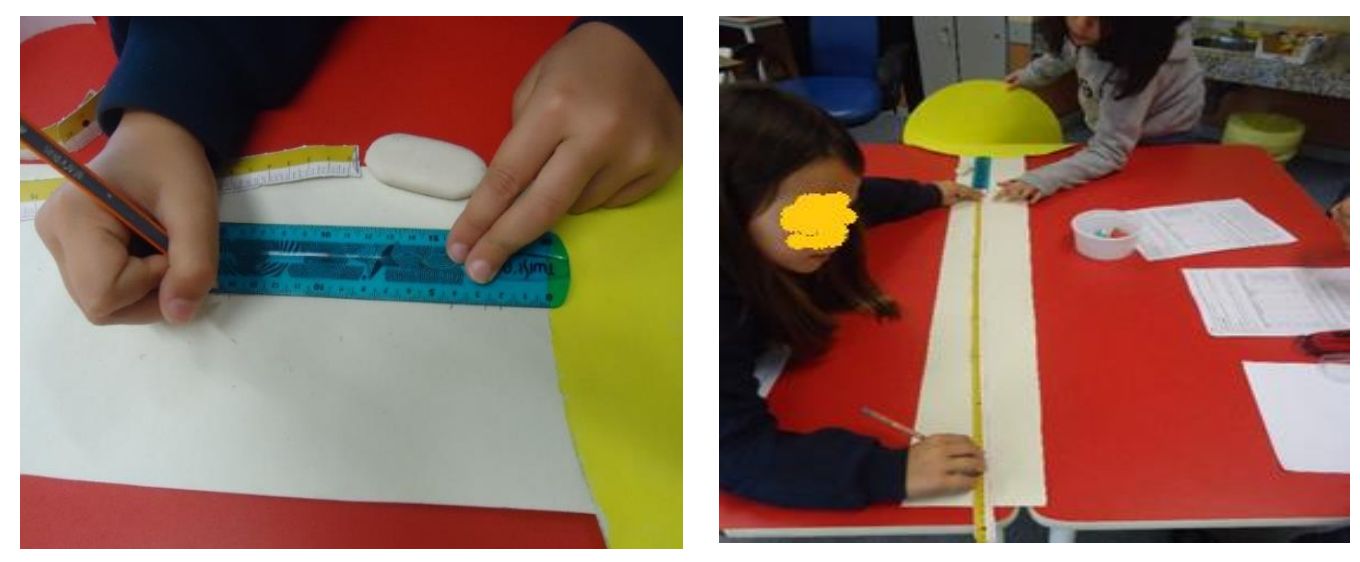

Figura 4 - Marcação dos raios das órbitas dos planetas.

Fonte: Observação da aula (fotos da 1. a autora).

A professora começou por pedir aos alunos para marcarem as distâncias, relativas aos 
DOI: http://dx.doi.org/10.20396/zet.v26i3.8651176

raios das órbitas dos planetas, no retângulo de papel branco, de acordo com os dados indicados na tabela que integra uma ficha de trabalho (Figura 4). Abaixo segue um pequeno extrato dos diálogos entre os alunos.
Aluno1: Mercúrio está a $2 \mathrm{~cm}$.
Aluno2: $\quad$ Agora marca Vénus a 2,7 cm.
Aluno3: $\quad$ Marte está a $25 \mathrm{~cm}$. Olha! Não dá com a régua!!!
Aluno4: $\quad$ Usa a fita métrica.

Depois de marcados os raios das órbitas de todos os planetas passou-se à modelação dos mesmos. Os planetas foram construídos pelos alunos, respeitando a escala e as cores indicadas na tabela da ficha (Figura 5).
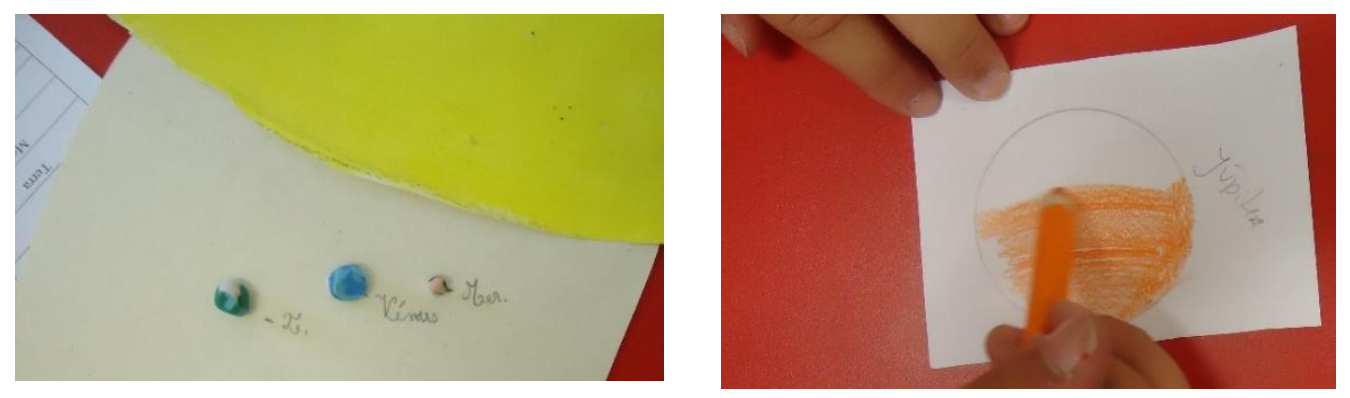

Figura 5 - Modelação dos planetas.

Fonte: Observação da aula (fotos da 1. a autora).

Os planetas mais pequenos foram modelados com plasticina de acordo com as cores indicadas. Os maiores, como é o caso de Júpiter e Saturno, foram desenhados num papel com a ajuda de um compasso e posteriormente pintados de acordo com a cor indicada. A professora orquestrou o trabalho dos alunos promovendo a sua autonomia:

Professora: Vamos fazer Mercúrio com um bocadinho de preto, ... $2 \mathrm{~mm}$... Vejam no paquímetro o tamanho: é muito, muito pequenino.

[A professora confirma com o paquímetro se as dimensões dos planetas, modelados pelos alunos estão corretas]

Professora: Vamos começar por construir os planetas maiores. Quais são eles?

Aluno: $\quad$ São Júpiter e Saturno.

Professora: Qual é o seu diâmetro?

Aluno: Não sei!

Professora: Vê na tabela que está na folha que vos dei.

Aluno: Ah! O Júpiter tem $6 \mathrm{~cm}$ e o Saturno tem $5 \mathrm{~cm}$.

Professora: O que é o diâmetro? [A professora desenha uma circunferência no quadro e traça o diâmetro da mesma]

Professora: Se Júpiter tem $6 \mathrm{~cm}$ de diâmetro, vamos abrir o compasso com 
DOI: http://dx.doi.org/10.20396/zet.v26i3.8651176 quanto? Júpiter é no papel. Vamos abrir o compasso em quanto?

Aluna: $\quad 6 \mathrm{~cm}$.

Professora: Não! $6 \mathrm{~cm}$ é o diâmetro. [A professora volta ao quadro para explicar o que é o diâmetro.] Oh Carolina, se vais traçar a circunferência, vais abrir o compasso de que tamanho? Do tamanho do diâmetro?

Aluna: Não! É do raio. São $3 \mathrm{~cm}$.

Professora: Muito bem!

Depois de todos os planetas moldados e colados nas marcações assinaladas, a professora pediu aos alunos para resolverem um conjunto de exercícios apresentados na ficha de trabalho inicialmente distribuída.

Os vários modelos com o Sol e planetas construídos pelos alunos foram afixados na parede da sala para todos os alunos os poderem observar. De seguida, a professora procurou aferir se havia diferenças relativamente às perceções iniciais dos alunos.

Professora: Qual a diferença entre o que desenharam antes e o que fizeram agora?

Alunos: As cores! Nomes dos planetas. A ordem dos planetas.

Professora: Carolina mais diferenças! Ali os planetas estão muito chegados uns dos outros. [A professora aponta para os primeiros desenhos feitos pelos alunos]

Aluna: $\quad$ Agora estão mais afastados. [Referindo-se à modelação realizada na aula]

Professora: Alguns meninos escreveram que os planetas andavam às cambalhotas. É assim?

Alunos: $\quad$ Não! Andam à volta do Sol.

No final da sessão, foi realizada uma entrevista semiestruturada, onde a professora reforçou que criou a atividade inspirada na formação e recorrendo à internet, tal como tinha sido exemplificado no workshop de Astronomia. Além disso, ela refere que: "desta forma, os alunos participam mais ativamente e aprendem melhor (...)" (Entrevista, 5/05/2017).

A 5. ${ }^{a}$ sessão foi realizada duas semanas mais tarde e visava analisar a velocidade de cada planeta e o tempo que demoram a dar uma volta em torno do Sol. Para realizar a modelação, esta sessão foi combinada no ginásio da escola. Os alunos foram organizaram em 8 grupos, representando cada grupo um dos 8 planetas. A cada grupo foi entregue uma ficha com dados sobre os planetas, nomeadamente raios das órbitas e respetivas velocidades em torno do Sol.

O círculo central do ginásio representava o Sol. O grupo do Mercúrio foi o primeiro a traçar a respetiva órbita com giz no chão do ginásio. Com uma fita métrica começaram por marcar pontos correspondentes ao raio orbital enquanto os colegas de grupo os uniam para traçar a órbita (Figura 6). 
DOI: http://dx.doi.org/10.20396/zet.v26i3.8651176
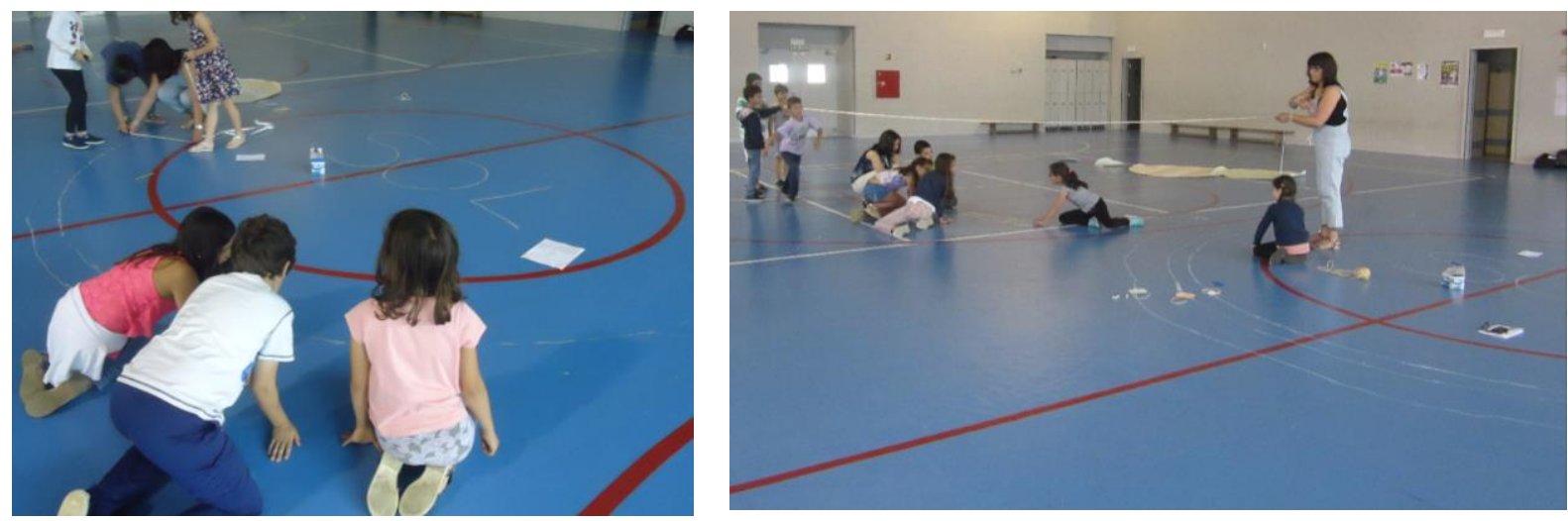

Figura 6 - Marcação da órbita dos planetas recorrendo a uma fita métrica.

Fonte: Observação da aula (fotos da 1. a autora).

De seguida foi a vez do grupo de Vénus e assim sucessivamente. Uma vez desenhadas as órbitas, os planetas (previamente desenhados) foram alinhados de acordo com a sua posição em relação ao Sol. Cada planeta tinha uma corda cujo comprimento era proporcional à respetiva velocidade (Figura 7). Quanto maior a velocidade, maior o comprimento da corda.
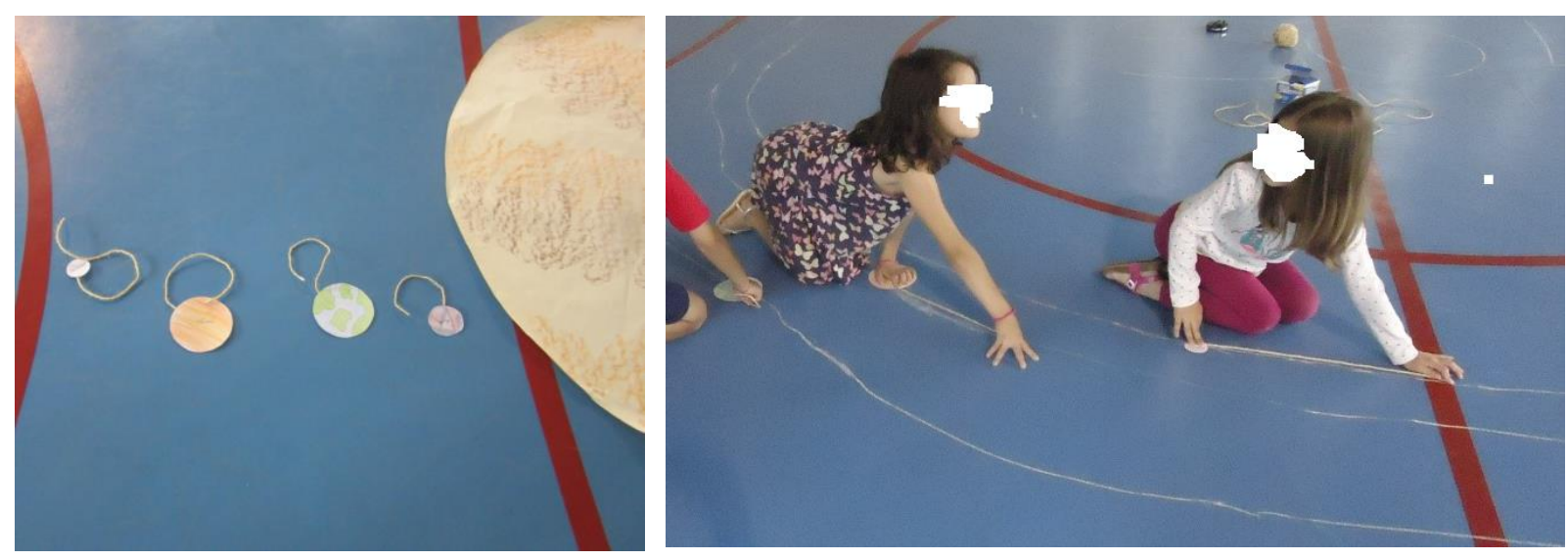

Figura 7 - Os planetas com as cordas (esquerda) e a "corrida" (direita).

Fonte: Observação da aula (fotos da 1. ${ }^{\mathrm{a}}$ autora).

A professora explicou que cada vez que tocasse o apito (duração de cerca de um segundo) os alunos avançavam com o respetivo planeta, ao longo da órbita, a distância correspondente ao comprimento da corda. Enquanto o colega do grupo avançava com o planeta em torno do Sol, os restantes colegas ficavam encarregues de contar o número de apitos da professora. Depois das explicações, a professora começou por colocar algumas questões como se exemplifica de seguida:

Professora: Qual o planeta que vai chegar primeiro?

Aluno1 : Sei lá!

Aluno2: É o Mercúrio. Não vês que tem a corda maior?

Aluno3: E também tem a órbita mais pequena!

Após alguma discussão, deu-se início à respetiva "corrida" com um apito. Quando o 
DOI: http://dx.doi.org/10.20396/zet.v26i3.8651176

Mercúrio atingiu um quarto de volta a professora mandou parar e perguntou ao grupo:

Professora: Quantos apitos foram dados até Mercúrio dar um quarto de volta?

Aluno: Foram 7.

Quando Mercúrio completou a primeira volta a professora coloca novas questões. O mesmo para Vénus e para os planetas seguintes. Quando finalmente Neptuno atingiu um quarto de volta:

Professora: Quantos apitos foram dados até Neptuno dar um quarto de volta?

\section{Aluno: $\quad$ Foram 10.}

A atividade continuou e, no final, a professora fez uma reflexão com os alunos sobre o que aprenderam e estes resolveram mais exercícios propostos na ficha.

No final da formação a professora Manuela apresentou o seu relatório final (2/06/2017), o qual não só ilustra muitas das tarefas que realizou com os respetivos alunos como mostra o impacto que a formação teve nas práticas realizadas:

A prática desta Ação de Formação permitiu-me apreender novos percursos de aprendizagem no que respeita à diversidade de temas abordados, tendo em conta: a organização de atividades propostas; a valorização dos conhecimentos dos alunos; a criação de linhas de orientação e o reconhecimento de alguns materiais, capazes de melhorar as competências inerentes às aprendizagens das Ciências Experimentais.

Tal como outros professores, a professora Manuela também refere o interesse dos alunos pelos tópicos e pela forma como foram abordados. Além disso, a interdisciplinaridade observada nas suas aulas também é referida no relatório, indo para além das aplicações à Matemática:

Toda a formação acabou por nos auxiliar a investir na abordagem de temas curriculares, de uma forma diferente, em contexto de sala de aula, onde os alunos demonstram um interesse extraordinário e revelaram-se muito determinados para a realização das tarefas propostas. É de salientar também que as atividades que desenvolvi com os meus alunos tiveram uma relação com todas as áreas disciplinares (interdisciplinaridade): Matemática, no que respeita aos domínios dos Números e Operações, Geometria e Medida e Organização e tratamento de dados; Português, na construção de textos; Expressões, no que respeita à moldagem e à pintura; Estudo do Meio, onde foram abordados conteúdos programático relacionado com o Sistema Solar e "À Descoberta dos Materiais e Objetos" e Cidadania que visou contribuir para a formação de pessoas responsáveis, autónomas, que conhecem e exercem os seus deveres em diálogo e no respeito pelos outros.

$\mathrm{O}$ apoio prestado pelos formadores também foi muito valorizado pela professora:

Também enalteço o interesse dos formadores no apoio à concretização das aulas, no que respeita à informação que nos proporcionaram assim como a atenção e a valorização do que lhes foi apresentado.

Tal como os outros professores, neste apoio as visitas às aulas dos professores são destacadas:

Para mim, também foi inédito, numa ação de formação os formadores deslocarem-se à escola para, junto dos alunos, desenvolverem atividades e abordarem conteúdos, 
DOI: http://dx.doi.org/10.20396/zet.v26i3.8651176

utilizando materiais diversos e muito concretizadores de uma forma muito motivadora e gratificante para os alunos.

Finalmente, o ambiente colaborativo desenvolvido entre os participantes nesta formação constitui um aspeto muito positivo:

A partilha de materiais, ideias e atividades foi, quanto a mim, um ponto muito positivo assim como a envolvência prática de todos os elementos constituintes desta formação: formadores, formandos e alunos.

Face ao exposto verifica-se que a professora Manuela ganhou CC e CP o qual é reconhecido pela própria nas suas reflexões e também é visível no trabalho que desenvolveu com os alunos. O PDP teve impacto nesta professora que ganhou novos conhecimentos e inovou as suas práticas criando e implementando atividades que não faziam parte da sua prática habitual.

\section{Considerações finais}

Neste estudo procurámos descrever o impacto de um PDP que envolve atividades experimentais hands-on de Astronomia, no desenvolvimento de práticas de ensino da Matemática, de professores do 1. ${ }^{\circ}$ CEB. De acordo com Murphy et al. (2015), a inovação nas práticas dos professores é um aspeto chave para indicar a eficácia de um PDP. Deste ponto de vista, consideramos que este PDP teve impacto positivo nos professores, nomeadamente na professora Manuela que implementou atividades experimentais de Astronomia e tirou partido das mesmas, para propor e desenvolver tarefas de Matemática, destinadas aos seus alunos, as quais não faziam parte das suas práticas habituais.

A aquisição de CC sobre os tópicos abordados nos 2 workshops de Astronomia também ficou patente pela comparação dos resultados dos dois testes diagnósticos, aplicados antes e depois dos referidos workshops. Entendemos que esta melhoria no CC está relacionada com a metodologia usada no PDP, onde as abordagens hands-on realizadas enquanto se apresentavam os conteúdos teóricos desempenham um papel fundamental. De facto, este foi um aspeto bastante evidenciado nos testemunhos dos professores apresentados nos seus relatórios individuais. A mesma abordagem hands-on também contribuiu para enriquecer o CP através da forma exemplificativa de implementar uma atividade experimental, tal como referiram muitos professores.

Para além de um programa com uma forte componente prática exemplificativa de atividades experimentais hands-on, destacamos, ainda, o ambiente colaborativo deste programa, bem como o apoio prestado aos professores, nomeadamente as visitas às escolas, como as principais estratégias que contribuíram para a eficácia do mesmo. Estas constatações estão de acordo com vários autores que também defendem a importância de apoiar os professores no âmbito do seu desenvolvimento profissional (Murphy et al., 2015; Zehetmeier et al., 2015). Tal como referido por Zehetmeier et al. (2015, p. 168) que defende que "as inovações devem ser apropriadas pelas pessoas que as implementam e transformadas na sua prática pessoal, de forma a terem efeitos reais", entendemos que foi o que aconteceu com a 
DOI: http://dx.doi.org/10.20396/zet.v26i3.8651176

professora Manuela e, por conseguinte, as inovações foram apropriadas por ela.

A análise e discussão dos dados, mostra-nos que é possível motivar os professores pelo tema da Astronomia, de forma a conseguirem propor tarefas de Matemática adequadas aos domínios de Números e Operações, Geometria e Medida e Organização e Tratamento de Dados. A falta de CC, que foi identificada como causadora de insegurança nos professores, pode ser alterada através de um programa de formação adequado. Ao adquirirem este conhecimento os professores ganham confiança para inovar e acabam por manifestar CP para criar e aplicar tarefas adequadas aos seus alunos, como ocorreu com o caso descrito neste texto, a exemplo do referido na literatura (Ball et al. 2008).

Concluímos que o PDP teve impacto nas práticas dos professores, que ganharam motivação e confiança para as inovar, trabalhando a Matemática, a partir de recursos de Astronomia, promovendo a interdisciplinaridade, tal como exemplificado no estudo de caso apresentado.

\section{Limitações deste estudo e trabalho para o futuro}

Apesar dos resultados aqui apresentados reconhecemos que não apresentámos um estudo exaustivo com todos os professores que participaram no PDP. Alguns dos professores que participaram no programa, apesar de reconhecerem a importância de implementar este tipo de abordagem, acabam por não mostrar evidências de implementação das mesmas, principalmente no que diz respeito à promoção da interdisciplinaridade.

Uma possível explicação talvez esteja relacionada com o facto de não se ter desenvolvido uma colaboração tão próxima com estes professores como no caso do exemplo aqui apresentado. Este será um aspeto a investigar no futuro, no sentido de apurar melhor uma explicação e como intervir de modo a se conseguir que esta abordagem passe a ser uma prática habitual, entre os professores.

\section{Agradecimentos:}

Este trabalho foi apoiado por fundos da Fundação para a Ciência e Tecnologia, no contexto do projeto UID/CED/02861/2016

\section{Referências}

Abell, S. K., \& McDonald, J. T. (2006). Envisioning a curriculum of inquiry in the elementary school. In Flick, L. B. \& Lederman, N. G. (Eds.), Scientific inquiry and nature of science: Implications for teaching, learning, and teacher education (pp. 249261). Dordrecht, Boston: Springer.

Abrahams, I., Reiss, M. J., \& Sharpe, R. (2014). The impact of the getting practical: Improving practical work in science continuing professional development programme on teachers' ideas and practice in science practical work. Research in Science \& Technological Education, 32(3), 263-280. 
DOI: http://dx.doi.org/10.20396/zet.v26i3.8651176

Afonso, M., Neves, I., \& Morais, A. M. (2005). Processos de formação e sua relação com o desenvolvimento profissional dos professores. Revista de Educação, 13(1), 5-37.

Ball, D. L. (2003). Mathematics in the $21^{\text {st }}$ century: What mathematical knowledge is needed for teaching mathematics. Paper presented at the Secretary's Summit on Mathematics, U.S. Department of Education, Washington, DC.

Ball, D. L., Thames, M. H., \& Phelps, G. (2008). Content knowledge for teaching what makes it special? Journal of teacher education, 59(5), 389-407.

Bannan-Ritland, B. (2000). Teacher Design Research. An emerging paradigm for teachers' professional development. In A. E. Kelly \& R. A. Lesh (Eds.), Handbook of Research Design in Mathematics and Science Education (pp. 246-262). Mahwah, NJ: Lawrence Erlbaum.

Beane, J. A. (1995). Curriculum integration and the disciplines of knowledge. The Phi Delta Kappan, 76(8), 616-622.

Berlin, D. F., \& Lee, H. (2005). Integrating science and mathematics education: Historical analysis. School Science and Mathematics, 105(1), 15-24.

Baxter, J. A., Ruzicka, A., Beghetto, R. A., \& Livelybrooks, D. (2014). Professional development strategically connecting mathematics and science: The impact on teachers' confidence and practice. School Science and Mathematics, 114(3), 102-113.

Cobb, P., Jackson, K., \& Dunlap, C. (2014). Design research: An analysis and critique. Handbook of international research in mathematics education, 481-503.

Cohen, L., Lawrence, M., \& Keith, M. (2007). Research Methods in Education. 6th Edition. Taylor and Francis Group.

Costa, M. C.; \& Domingos, A. (2017). Innovating teachers' practices: potentiate the teaching of mathematics through experimental activities. In CERME 10: Dooley, T., \& Gueudet, G. (Eds.) (2017). Proceedings of the Tenth Congress of the European Society for Research in Mathematics Education (CERME 10, February 1-5, 2017, pp. 28282835). Dublin, Ireland: DCU Institute of Education and ERME.

Fleisch, D.; Kregenow, J. (2013) A Student's Guide to the Mathematics of Astronomy. Cambridge University Press.

Geiger, V., Goos, M., Dole, S., Forgasz, H., \& Bennison, A. (2014). Devising principles of design for numeracy tasks. In Curriculum in focus: Research-guided practice: Proceedings of the 37th annual conference of the Mathematics Education Research Group of Australasia (pp. 239-246).

Hewson, P.W. (2007). Teacher Professional Development in Science. In S. K., Abell \& N. G., Lederman, Handbook of research on science education (pp. 1177-1203). New York: Routledge. 
DOI: http://dx.doi.org/10.20396/zet.v26i3.8651176

Kalkan, H., \& Kiroglu, K. (2007). Science and nonscience student's ideas about basic astronomy concepts in preservice training for elementary school teachers. Astronomy Education Review, 6(1), 15-24.

Keeley, P.; Sneider, C. I. (2012). Uncovering student ideas in astronomy: 45 formative assessment probes. NSTA Press.

Lavonen, J., Byman, R., Juuti, K., Meisalo, V., \& Uitto, A. (2005). Pupil interest in physics: a survey in Finland. Nordic Studies in Science Education, 1(2), 72-85.

Luft, J., Hill, K., Nixon, R., Campbell, B.; Dubois, S. The knowledge needed to teach science: Approaches, implications, and potential research. In annual meeting of ASTE. Portland, OR, 2015.

Ministério da Educação (ME). (2013) Metas Curriculares de Matemática. Programa de Matemática para o ensino básico - $1 .^{\circ}$ Ciclo. Lisboa: Departamento da Educação Básica. Retirado em 15 de junho, 2018 de: http://www.dge.mec.pt/matematica.

Ministério da Educação (ME). (s. d.) Programa de Estudo do Meio para o ensino básico - 1. ${ }^{\circ}$ Ciclo. Lisboa: Departamento da Educação Básica. Ministério da Educação. Retirado em 15 de junho, 2018, de: http://www.dge.mec.pt/ estudo-do-meio.

Morgan, D. L. (1997). The focus group guidebook (Vol. 1). Sage publications.

Murphy, C., Smith, G., Varley, J., \& Razı, Ö. (2015). Changing practice: An evaluation of the impact of a nature of science inquiry-based professional development programme on primary teachers. Cogent Education, 2(1), 1077692.

Osborne, J., \& Dillon, J. (2008). Science education in Europe: critical reflections. London: The Nuffield Foundation.

Rocard, M., Csermely, P., Jorde, D., Lenzen, D., Walberg-Henriksson, H., \& Hemmo, V. (2007). Science education now: A renewed pedagogy for the future of Europe. Bruxelas: Comissão Europeia.

Treacy, P., \& O’Donoghue, J. (2014). Authentic Integration: a model for integrating mathematics and science in the classroom. International Journal of Mathematical Education in Science and Technology, 45(5), 703-718.

Trumper, R. (2003). The need for change in elementary school teacher training - a crosscollege age study of future teachers' conceptions of basic astronomy concepts. Teaching and Teacher Education, 19(3), 309-323.

Zawojewski, J., Chamberlin, M., Hjalmarson, M. \& Lewis, C. (2008). Developing design studies in mathematics education professional development: Studying teachers' interpretive systems. Handbook of design research methods in education: Innovations in science, technology, engineering, and mathematics learning and teaching, 216-245. 
DOI: http://dx.doi.org/10.20396/zet.v26i3.8651176

Zehetmeier, S., Andreitz, I., Erlacher, W., \& Rauch, F. (2015). Researching the impact of teacher professional development programmes based on action research, constructivism, and systems theory. Educational action research, 23(2), 162-177. 